"Corporate governance mechanisms and bank performance: evidence from the Greek banks during crisis period"

\begin{tabular}{|c|c|c|}
\hline AUTHORS & \multicolumn{2}{|l|}{$\begin{array}{l}\text { Andreas G. Georgantopoulos } \\
\text { loannis Filos }\end{array}$} \\
\hline ARTICLE INFO & \multicolumn{2}{|c|}{$\begin{array}{l}\text { Andreas G. Georgantopoulos and loannis Filos (2017). Corporate governance } \\
\text { mechanisms and bank performance: evidence from the Greek banks during crisis } \\
\text { period. Investment Management and Financial Innovations, 14(1-1), 160-172. } \\
\text { doi:10.21511/imfi.14(1-1).2017.02 }\end{array}$} \\
\hline DOI & \multicolumn{2}{|c|}{ http://dx.doi.org/10.21511/imfi.14(1-1).2017.02 } \\
\hline RELEASED ON & \multicolumn{2}{|l|}{ Friday, 28 April 2017} \\
\hline RECEIVED ON & \multicolumn{2}{|l|}{ Saturday, 31 December 2016} \\
\hline ACCEPTED ON & \multicolumn{2}{|l|}{ Wednesday, 22 February 2017} \\
\hline JOURNAL & \multicolumn{2}{|c|}{ "Investment Management and Financial Innovations" } \\
\hline ISSN PRINT & \multicolumn{2}{|l|}{$1810-4967$} \\
\hline ISSN ONLINE & \multicolumn{2}{|l|}{$1812-9358$} \\
\hline PUBLISHER & \multicolumn{2}{|c|}{ LLC "Consulting Publishing Company "Business Perspectives" } \\
\hline FOUNDER & \multicolumn{2}{|c|}{ LLC "Consulting Publishing Company "Business Perspectives" } \\
\hline 0 & 5 & $\begin{array}{l}\text { ニこ: } \\
\text { 三こ }\end{array}$ \\
\hline NUMBER OF REFERENCES & NUMBER OF FIGURES & NUMBER OF TABLES \\
\hline 40 & 0 & 5 \\
\hline
\end{tabular}

(c) The author(s) 2023. This publication is an open access article. 
Andreas G. Georgantopoulos (Greece), loannis Filos (Greece)

\title{
Corporate governance mechanisms and bank performance: evidence from the Greek banks during crisis period
}

\begin{abstract}
This paper is the first research attempt that investigates the impact of a large number of corporate governance mechanisms on the performance of Greek banks, employing widely accepted in the literature of corporate governance econometric models. Results indicate that system GMM models are more suitable methodological tools than pooled OLS and fixed effects models to address well-known econometric problems, such as endogeneity, simultaneity and unobserved heterogeneity of individual banks. The findings, as derived from the application of GMM models, imply that increasing the board size and the number of independent directors can both have positive impact on the performance of Greek banks, but only up to a certain point. Thus, bank efficiency will increase as board size and the proportion of independent directors grow up to a point where these relationships hit a maximum from which bank performance decreases. Our multi-model estimations failed to trace any significant contribution of the number of female and foreign directors on the performance of Greek banks. Finally, the dual appointment of a CEO as Chairman appears to affect negatively two out of four proxies of bank performance. Overall, the results provide support for the positive impact of corporate governance mechanisms on the performance of Greek banks. The significance of these findings increases, considering that the period under study (2008-2014) is marked by high market volatility and uncertainty due to the well-known debt crisis that plagues Greece since the beginning of 2008 .
\end{abstract}

Keywords: banking, corporate governance, crisis, board structure.

JEL Classification: C52, G34, G21.

Received on: $31^{\text {th }}$ of December, 2016.

Accepted on: $22^{\text {th }}$ of February, 2017.

\section{Introduction}

The recent global financial crisis motivated a large number of researchers to assess the impact and usefulness of corporate governance mechanisms on the performance of banking institutions. In the academic literature, it is widely accepted that banking institutions play a crucial role in all modern economic systems. Thus, ensuring the financial stability of the banking sector can only be seen as a top priority for national economies worldwide in order to succeed in their efforts towards long-term prosperity. Under this notion, the Basel Committee on Banking Supervision (BCBS) (2006) urges banks to comply with the values and framework of corporate governance (CG) in order not only to increase transparency, but also to regain the society's confidence in the banking system. Moreover, efficiently governed banks can be seen as an additional protection shield for potential investors and shareholders, since due to their crucial intermediary role, the banking industry is in a unique position to convey the values and codes of corporate governance across all business sectors of a country's economy (Caprio and Levine, 2002).

(C) Andreas G. Georgantopoulos, Ioannis Filos, 2017

Andreas G. Georgantopoulos, Dr., Department of Public Administration, Panteion University of Social and Political Sciences, Greece.

Ioannis Filos, Associate Professor, Department of Public Administration,

Panteion University of Social and Political Sciences, Greece.

This is an Open Access article, distributed under the terms of the Creative Commons Attribution 4.0 International license, which permits unrestricted re-use, distribution, and reproduction in any medium, provided the original work is properly cited.
Although the complexity and variety of the banking products does not favor the reduction of information asymmetry, the second pillar of Basel II as issued by the Basel Committee on Banking Supervision (2005) and the Dodd-Frank Act ${ }^{1}$ both highlight the importance of board structure and the necessity to increase the numbers of independent board members in banking boards as not only to protect the interests of the minority shareholders, but also to ensure improved monitoring efficiency, accountability and financial transparency.

Our paper aims to contribute to the existing pool of knowledge on corporate governance through assessing the impact of a significant number of corporate governance mechanisms on bank value for Greece, a country that is a member of the European Monetary Union. The main motive of this study is to evaluate and discuss the capability of the Greek banks' board of directors (BoD) to monitor and motivate bank managers under the assumption that efficiently governed banks lead to motivated bank managers and as a result increased bank efficiency. Second, this paper focuses on assessing the contribution of the existing Corporate Governance regulatory framework on the performance of Greek banking institutions by employing a representative sample of thirteen Greek banks that hold altogether $99 \%$ (on average) of the country's market share.

\footnotetext{
${ }^{1}$ Internet Source: "Dodd-Frank Wall Street Reform and Consumer Protection Act": https://www.sec.gov/about/laws/wallstreetreformcpa.pdf, retrieved on June 6, 2016.
} 
This study is influenced by the previous works of Andres and Vallelado (2008) and Adams and Mehran (2005, 2012). However, our empirical models and findings extend the above papers in a number of interesting and innovative ways. First, this is the only study that narrows its research interest on assessing the impact of corporate governance mechanisms on bank performance for the case of Greece and for a period ranging from the beginning of the severe sovereign debt crisis in 2008 until 2014. Considering that this crisis continues to plague the Greek economy until present, this paper offers a unique opportunity to answer the question whether significant relationships between corporate governance mechanisms and bank performance can be traced for a national economy that is characterized by high market volatility and financial instability. Previous studies focused on corporate governance issues for the case of Greece (Grose et al., 2014) limit their analysis on a theoretical presentation of the Greek CG regulatory framework, they analyze the implementation of the CG system and present their conclusions on the compliance of listed companies in the Athens Stock Exchange (ASE) with the relevant Greek CG legal framework. These studies lack empirical analysis, they do not concentrate on the banking sector and do not provide exhaustive results to document the impact of CG mechanisms on bank efficiency. Thus, our paper aims to enrich the very limited governance literature for the case of Greece by producing for first time, to the best of our knowledge, the most complete set of empirical data used to assess the corporate governance bank performance nexus for the Greek banking sector.

Second, this paper employs multiple measures of bank efficiency. Doing so, we can crosscheck the robustness of the produced empirical findings. For this purpose, we use four alternative proxies of bank performance (i.e., net interest margin, return on average equity, pre-tax operating income and return on average assets) documenting and assessing the persistence of significant links that are traced from the empirical applications on our dataset ${ }^{2}$.

Third, this paper present empirical results from the application of three widely used in the related literature econometric tools; the pooled OLS, the fixed effects (within estimator) and the two-step system GMM estimator. This approach enables to draw comparative conclusions and to test the

\footnotetext{
${ }^{2}$ Considering that our dataset does not include only banks that are listed in Athens Stock Exchange (ASE), we decide not to employ Tobin's Q as a proxy of bank performance in our research. Nevertheless, we support that even if all sample banks were listed in ASE, Tobin's Q would not be an appropriate proxy for bank performance, since the period under study (2008-2014) is characterized by high market volatility and financial distress, as an aftermath of the sovereign debt crisis.
}

validity of these methods and the robustness of the empirical results. Our empirical analysis for the case of the Greek banks supports the superiority of the GMM methodology over pooled OLS and fixed effects models to treat classical econometric problems that arise when dealing with dynamic panel data and socio-economic variables, such as the endogeneity of explanatory variables, simultaneity and unobserved heterogeneity of the sample banks.

Fourth, this study provides not only unique empirical findings for the case of the Greek banking sector, but also presents one of the most complete pictures of board structure and its impact on bank performance by using most of the available board structure characteristics that past literature on corporate governance has focused until present. We examine a comprehensive set of board structure variables (i.e. board size and the proportions of $\mathrm{BoD}$ members who are independent, female, and foreign) and their contribution on bank performance under the scope that the BoD is the "backbone" of a firm's internal governance.

Fifth, we consider that a bank's board could become larger due to an M\&A activity by accommodating additional board members from the acquired/merged banks. To address this issue that could lead to biased results, we control our sample banks for M\&A activity with the inclusion of an M\&A dummy.

The rest of the paper is organized as follows: section 1 presents the relevant literature and our empirical hypotheses concerning corporate governance mechanisms. Section 2 describes the sample, variables and econometric models. Section 3 presents the results, while last section concludes.

\section{Related literature and empirical hypotheses}

1.1. Board size and bank performance. The governance literature remains inconclusive whether large boards are beneficial for the organization or not. Conclusions vary not only because of differences in culture, governance regulatory frameworks or even structural differences that each country exhibits. Unfortunately, even studies that investigate the same sector provide contradictory evidence. As a result, the banking sector is not an exception. The few published papers dealing with the impact of board size on bank performance present very different results and very convincing arguments as to whether large or small boards tend to promote bank efficiency.

A sizeable body of literature supports that large boards negatively affect firm performance not only 
due to increased coordination and communication costs, but also to free-rider problems. Smaller boards, on the other hand, are more flexible to make quick decisions and each director has more time available to express his opinion and to be heard (Eisenberg et al., 1998; Yermack, 1996). In contrast, other studies suggest that large boards promote firm performance mostly due to increased monitoring capabilities and pluralism of opinions to approach each problem that the organization faces (Adams and Mehran, 2012; Coles et al., 2008; Linck et al., 2008). Another strand of literature presents empirical results supporting that each company and sector must have an optimum number of directors appointed in the $\mathrm{BoD}$ to avoid the negative effects that both small and large boards have on firm performance (Raheja, 2005; Andres and Vallelado, 2008). Finally, another group of studies find no evidence to support the significant impact of board size on performance (James and Joseph, 2015; Wintoki et al., 2012). Hence, the first two null hypotheses can be stated as follows:

$H_{01}$ : Board size has no significant impact on bank performance.

$H_{02}$ : There is no optimal number of directors that maximizes bank performance.

1.2. Independent directors and bank performance. In the wake of Enron and WorldCom scandals, a growing body of governance literature supports that independent directors serve as better monitors of managerial decisions, since it is believed that they are not willing to jeopardize their own reputation in favor of executive managers' benefits. Considering that independent board members are not tied to the company's culture and "ways of doing business", they are free to provide their objective view and monitor the company's management protecting the interests of shareholders, reducing the conflicts of interest and as a result to promote firm efficiency, earnings quality and even the market value of the firm's stocks (Nguyen and Nielsen, 2010; Klein, 2002). However, another strand of literature argues that independent board members lack the necessary skills and familiarity with the company's culture and unique characteristics. Therefore, their active involvement with the company's decision-making process may lead to less optimal decisions damaging firm performance (Adams and Mehran, 2003; Agrawal and Knoeber, 1996; Harris and Raviv, 2008; Raheja, 2005). A different strand of literature focused on the banking industry provides empirical evidence documenting an inverted Ushaped relation between the proportion of independent board members and bank performance (Adams and Mehran, 2012; Andres and Vallelado,
2008), while others find no evidence to support the significant impact of independent directors on firm performance (Coles et al., 2008; Hermalin and Weisbach, 2003; James and Joseph, 2015). To test the impact of independent directors on the performance of Greek banks, we develop the following hypotheses in null form:

$H_{03}$ : Independent directors have no significant impact on bank performance.

$H_{04}$ : There is no optimal number of independent board members that maximizes bank performance.

1.3. Gender diversity and bank performance. The literature shows that female representation has rapidly increased, especially in Western countries during the last two decades (Catalyst, 2010). The argument behind the growing interest of the literature in gender diversity is that increased gender diversity may affect positively not only stock prices (Gul et al., 2011) and the attendance rates in board meetings (Adams and Ferreira, 2009), but also the firm's value (Carter et al., 2003). Moreover, women have to prove additionally their abilities and skills than men in order to reach managerial positions, which in turn, may motivate them becoming efficient directors and significant contributors of firm performance (Eagly and Carly, 2003).

Formal evidence linking gender diversity and bank performance are extremely limited in the governance literature. These few findings also report mixed results. To this respect, Liang et al. (2013) in their study on Chinese banks fail to support the hypothesis that female directors significantly affect bank performance, while Pathan and Faff (2013) suggest that gender diversity promotes bank efficiency for the case of large US bank holding companies. Based on the above discussion, our next testable null hypotheses are developed as follows:

$H_{05}:$ Female directors have no significant impact on bank performance.

$H_{06}$ : There is no optimal number of female board members that maximizes bank performance.

1.4. Foreign directors and bank performance. The examination of the relationship between the proportion of foreign directors that are appointed as board members and firm performance has raised the interest of the governance literature quite recently and this is the reason that only few published studies report evidence on this relationship. These studies are driven by the hypothesis that foreign directors may bring new technology, managerial skills and solutions to corporate problems through their experience from foreign companies. These differences - in terms of culture and alternative 
ways to treat business matters - can enrich the existing know-how of the firm's BoD and lead to higher firm performance.

The majority of these studies fail to find significant results on the foreign director-firm performance nexus, although it should be highlighted that the number of relevant studies is too few in order to draw firm conclusions (Liang et al., 2013; PeckLing et al., 2016). However, Hahn and Lasfer (2016) in their paper on UK firms support that only foreign directors with a non-executive role in the board do create firm value, but only when this board characteristic is associated with higher number of meetings. To enrich the limited existing governance literature on foreign board members, our next two null hypotheses are as follows:

$H_{07}:$ Foreign directors have no significant impact on bank performance.

$H_{08}$ : There is no optimal number of foreign board members that maximizes bank performance.

1.5. CEO-Chairman duality and bank performance. In the literature of corporate governance, the CEO-Chairman duality is defined as the dual appointment of the same individual to serve both roles. The majority of relevant studies agree that duality gives too much power to one executive (Pi and Timme, 1993; Adams et al., 2005). This, in turn, may hurt the interests especially of minority shareholders and diminish board independence (Yermack, 1996; Khanchel, 2007).

In contrast, other studies suggest that the disadvantages of separating the CEO and Chairman positions are more important than the benefits for the organization (Brickley et al., 1997; Deya et al., 2011), while Lorsch and Lipton (1993) claim that splitting titles may dilute the executive's power to provide effective leadership and create the potential for conflicts between the separate title holders. Hence, following the above analysis, our next null hypothesis is:

$H_{09}$ : The dual appointment of the CEO as Chairman does not significantly affect bank performance.

\section{Data analysis and empirical models}

2.1. Sampling procedures and composition. The sample of this paper consists of 13 Greek banks over the period 2008-2014, which is marked by the fiscal and financial crisis that hit Greece in 2008. Greece has not shown promising signs of recovery from the deep recession until present, although the Greek Government in cooperation with European and international institutions proceeded to several changes in the Greek fiscal policy to increase revenues from taxes accompanied by extensive restructuring in the Greek banking industry to mitigate the size and impact of the non-performing loans on the balance sheets of the Greek banks. Our strongly representative sample includes the four systemic Greek banks that possess the overwhelming $93 \%$ of market share on average during the period under study. Moreover, our sample includes two large investment banks, four smaller commercial banks, two financial intermediaries that provide factoring services and the largest in terms of assets cooperative bank in Greece. Considering the above, we managed to build a sample of Greek banks that is weakly unbalanced. Sample banks altogether own approximately $99 \%$ of the Greek banking assets. Therefore, it is fair to support that this paper covers almost the entire Greek banking industry and, thus, utilizing this sample we can obtain a very clear and complete picture on the corporate governance-bank performance relations for the case of the Greek banking industry. Overall, our sample covers 91 bank-year observations and all data included in this study refer at the end of the year ensuring sample uniformity.

All financial and accounting data were obtained exclusively from the Bankscope database, while all corporate governance data were hand-collected from the banks' annual reports accessed from each bank's official internet portal and from the official website of the Athens Stock Exchange. All sample banks publish their financial statements following the International Accounting Standards (IAS). Thus, it is safe to say that we have managed to avoid the production of biased estimations due to different application of accounting practices.

2.2. Bank performance variables. To validate our empirical findings, this paper employs four alternative measures of bank performance (see also Andres and Vallelado, 2008; Adams and Mehran, 2012). The first measure of bank performance is the return on average assets (ROA), which is defined as the net income before interest and taxes divided by the average book value of total assets. The second proxy used is the return on average equity (ROE), which is defined as the net income after taxes divided by the average book value of equity. The third measure is the net interest margin (NetInterest) defined as the net interest income divided by the average earning assets, while the fourth proxy of bank performance employed in this paper is the pretax operating income (PreTaxOI) defined as the operating income before taxes divided by the average book value of the bank's total assets.

2.3. Corporate governance variables. Extending previous literature, as presented in the literature review section, we managed to collect and input in 
one paper five different proxies of board characteristics: the number of board directors (BoardSize), the proportion of independent board members (IndepDir), the proportion of female board members (FemaleDir), the proportion of foreign board members (ForeignDir) and "ChairCEO", which is a dummy variable that takes the value of (1) in case the bank's CEO serves also as the bank's Chairman and (0) otherwise. Furthermore, we calculated the squared values of board size (BoardSizeSQ), the proportion of independent board members (IndepDirSQ), the proportion of female board members (FemaleDirSQ) and the proportion of foreign board members squared (ForeignDirSQ). Andres and Vallelado (2008) in their research used squares of board size and independent directors to capture significant inverted U-shaped relations. Our study, extends Andres and Vallelado's (2008) work to test whether concave relations could be traced between the squares of foreign and female directors and alternative proxies of bank performance.

2.4. Control variables. Following past banking literature on corporate governance, we include in our models a number of control variables, namely bank size (BankSize), which is calculated by the natural logarithm of bank assets and bank capital (BankCapital) as measured by the bank's total equity divided by total assets measuring the capital adequacy of each sample bank. Moreover, to further control our panel data for individual bank characteristics, we include several dummy variables; to grasp any mergers or acquisitions that take place within a bank year, we introduce the M\&A dummy variable that takes the value of (1) in case such an event occurs in a bank year and (0) otherwise. Following Liang et al. (2013), we include a dummy variable for listed banks (ListedBank) to control for increased privatization and more decentralized ownership that takes the value of (1) in case a sample bank is listed in the Athens Stock Exchange and (0) otherwise.

Finally, following Mollah and Zaman (2015), we control each bank whether is audited by a Big4 audit firm or not, introducing "Big4Audit" dummy that takes the value of (1) in case a bank is audited by a Big 4 company in a bank year and (0) otherwise. However, past literature does not highlight the fact that Big4 auditors provide services that are not limited to audit their client's financial statements, but within their responsibility as an external auditor is also to monitor the firm's internal control processes, the operating regulation, the compliance of the board's structure with the CG code and other elements that are included in the context of corporate governance. This study supports that these global audit firms through their international experience in audit and the provision of governance, regulatory and compliance services have a comparative advantage over their local competitors to ensure that their clients - especially the listed firms - operate in compliance with the CG code. Considering the above argumentation, we support that potential significant impact of the Big4 dummy variable on bank performance could imply that banks with a Big4 company appointed as an auditor are also governed more efficiently.

2.5. Full sample descriptive statistics. In Table 1, we present the descriptive statistics for the full sample. With respect to the measures of bank performance, we find that the mean ROA and ROE are $-2.05 \%$ and $-76.18 \%$, respectively. These significantly negative results are clear indicators of the deep recession that the Greek banking system has entered since 2008 because of the severe sovereign debt crisis and the unprecedented increase of the non-performing loans. Similar findings are tabulated for the cases of NetInterest and PreTaxOI in terms of mean results confirming the financial distress that the Greek banking system faces in the last nine years. Discussing the standard deviation of bank performance measures, we can document the high volatility that Greek banks experience throughout the crisis period under study with ROE volatility reaching the record high levels of 290.65 . This result indicates the high volatility of shareholders' returns and the uncertainty associated with investments in Greek banks.

Group B tabulates the descriptive statistics for the corporate governance variables. The mean board size of Greek banks (i.e., 12.24 members on average) appears to be significantly smaller than similar studies (e.g., Adams and Mehran, 2012; Liang et al., 2013; Andres and Vallelado, 2008). However, this differentiation can be attributed to the fact that the Greek economy and the Greek banking sector are relatively smaller in terms of GDP and bank size. However, the same explanation cannot be given when analyzing the mean results for the proportions of independent (24.49\%), female $(6.02 \%)$ and foreign $(8.62 \%)$ board members. These rates are significantly lower than those presented in similar studies, indicating that the penetration of the corporate governance culture in the Greek banking system follows a relatively slow pace. For example, Pathan and Faff's (2013) research on US banking institutions reports that US boards are comprised $24.51 \%$ from independent directors, $6.02 \%$ from female directors and $8.62 \%$ from foreign directors. The only board structure variable in our sample that seems to be in similar levels with previous literature is the proportion of foreign board 
members. Liang et al. (2013) calculate that large Chinese banks have $6 \%$ of foreign directors, which is $2.62 \%$ lower than our calculations. On average, $34 \%$ of the Greek banks exhibit the CEOChairman duality, which is significantly higher than the $9 \%$ on average for the case of Chinese banks (see Liang et al., 2013). Finally, $61 \%$ of our sample banks are audited by a Big 4 company. The only similar study that utilizes the Big4 dummy is Mollah and Zaman (2015) to the best of our knowledge. In their research, they find that on average $78.61 \%$ of their sample banks are audited by a Big4 company, which is higher than our bank sample results by $17.1 \%$.

Table 1. Full sample descriptive statistics

\begin{tabular}{|c|c|c|c|c|c|c|c|c|}
\hline Variable & Mean & Standard deviation & Minimum & Median & Maximum & Skewness & Kurtosis & $\begin{array}{c}\text { Jarque-Bera } \\
\text { P-Value }\end{array}$ \\
\hline \multicolumn{9}{|c|}{ Group A: bank performance variables } \\
\hline ROA & -2.05 & 6.79 & -34.03 & 0.07 & 5.83 & -3.10 & 13.48 & $0.00^{\star * *}$ \\
\hline ROE & -76.18 & 290.65 & -2131.01 & 0.55 & 55.43 & -5.44 & 34.87 & $0.00^{\star \star *}$ \\
\hline Netlnterest & 1.62 & 4.25 & -18.91 & 2.54 & 4.42 & -3.84 & 17.29 & $0.00^{\star \star *}$ \\
\hline PreTaxOI & -1.68 & 5.87 & -30.77 & 0.03 & 7.66 & -2.63 & 11.91 & $0.00^{\star * *}$ \\
\hline \multicolumn{9}{|c|}{ Group B: corporate governance variables } \\
\hline BoardSize & 12.25 & 3.64 & 7.00 & 12.00 & 21.00 & 0.43 & 2.47 & 0.14 \\
\hline BoardSizeSQ & 162.71 & 95.28 & 49.00 & 144.00 & 441.00 & 0.97 & 3.42 & $0.00^{\star \star \star}$ \\
\hline IndepDir & 24.49 & 20.74 & 0.00 & 21.45 & 83.35 & 1.16 & 4.53 & $0.00^{\star * \star}$ \\
\hline IndepDirSQ & 1025.41 & 1635.10 & 0.00 & 459.19 & 6944.51 & 2.75 & 9.81 & $0.00^{\star \star \star}$ \\
\hline FemaleDir & 6.02 & 5.81 & 0.00 & 6.26 & 20.00 & 0.26 & 1.67 & $0.02^{\star *}$ \\
\hline FemaleDirSQ & 69.70 & 83.00 & 0.00 & 39.07 & 400.00 & 1.23 & 4.45 & $0.00^{\star * *}$ \\
\hline ForeignDir & 8.62 & 14.19 & 0.00 & 0.00 & 50.00 & 1.66 & 4.51 & $0.00^{\star * \star}$ \\
\hline ForeignDirSQ & 273.37 & 602.36 & 0.00 & 0.00 & 2500.00 & 2.39 & 7.46 & $0.00^{\star \star *}$ \\
\hline ChairCEO & 0.34 & 0.48 & 0.00 & 0.00 & 1.00 & 0.69 & 1.48 & $0.00^{* \star *}$ \\
\hline \multicolumn{9}{|c|}{ Group C: control variables } \\
\hline BankSize & 8.41 & 2.21 & 5.04 & 8.10 & 11.71 & 0.41 & 1.67 & $0.01^{* *}$ \\
\hline BankCapital & 14.78 & 14.59 & -5.46 & 9.52 & 59.18 & 1.38 & 4.43 & $0.00^{\star * *}$ \\
\hline$M \& A$ & 0.27 & 0.44 & 0.00 & 0.00 & 1.00 & 1.12 & 2.26 & $0.00^{\star \star \star}$ \\
\hline Big4Audit & 0.61 & 0.49 & 0.00 & 1.00 & 1.00 & -0.49 & 1.21 & $0.00^{\star \star *}$ \\
\hline ListedBank & 0.55 & 0.50 & 0.00 & 1.00 & 1.00 & -0.17 & 1.03 & $0.00^{\star \star \star}$ \\
\hline
\end{tabular}

Notes: $(* * *),(* *)$ and $(*)$ denote significance at $1 \%, 5 \%$ and $10 \%$, respectively. This note also applies for all subsequent tables. The null hypothesis for the case of Jarque-Bera test is that the data are normally distributed.

Table 1 (Group C) reports the descriptive statistics for the control variables. The mean BankCapital is $14.78 \%$, is well above the minimum regulatory requirements as set by the Basel Committee on Banking Supervision (BCBS) ${ }^{3}$. These results imply that although the Greek banking system in under significant financial pressure, the capital adequacy of Greek financial intermediaries remains at very satisfying levels mainly due to liquidity assistance provided by organizations such as the European Central Bank, European Stability Fund and the International Monetary Fund. The mean results for ListedBank dummy variable shows that $54 \%$ of sample banks are listed in Athens Stock Exchange, while the mean calculations for the M\&A control variable implies that $27 \%$ of the sample bank years are years during which a merger/acquisition took place. As expected, the M\&A activity for the case of Greek banks is significantly higher in

\footnotetext{
${ }^{3}$ For additional information on minimum bank capital requirements, see Pillar 1 of the BCBS - Basel III; Web link:http://www.bis.org/bcbs/ basel3/b3summarytable.pdf, retrieved on May 21, 2016
}

comparison with similar studies. Indicatively, Pathan and Faff (2013) report that the mean results of M\&A activity for the case of US bank holding companies is only $9 \%$ during the period 1997-2011. Overall, our findings from the application of the Jarque-Bera test implies that all sample data are not normally distributed, except for BoardSize ${ }^{4}$.

2.6. Econometric models. Based on previous empirical literature on corporate governance, this study employs data in panel form, because it is considered the most reliable sampling method when dealing with cross-sectional data. In regard to our study, panel data method allows us to treat the individual bank characteristics (i.e., the

\footnotetext{
${ }^{4}$ To test for multicollinearity problems, we run the Pearson pair-wise correlations for all sample data. The empirical findings indicate that our variables do not suffer from multicollinearity, considering that the maximum calculated correlation is only -0.30 (between ListedBank and ChairCEO). Nevertheless, we find statistically significant and high correlations between Big4Audit and ListedBank (0.72) and between BankSize and ListedBank (0.86). Thus, we decided to exclude the "ListedBank" variable to avoid producing biased results due to collinearity problems. These results are available from the authors upon request.
} 
unobservable heterogeneity), due to differences in factors such as bank culture, ownership structure, and business philosophy that can lead our empirical analysis to biased results. Furthermore, another important issue that we have to address is the problem of simultaneity, since we cannot oppose to the possibility that at least some of the selected CG variables are simultaneously determined with bank performance. Therefore, to protect our empirical findings against biases that may be linked with the above problems, we need to employ appropriate methodological tools that can address in the same time frequently encountered econometric problems when dealing with socio-economic variables, such as endogeneity, heterogeneity, heteroskedasticity and simultaneity.

This study aims to contribute to the limited governance literature in banking through providing empirical evidence from the application of three widely accepted econometric methodologies (Pooled OLS, fixed effects/within estimator and two-step system GMM models) allowing us to assess their ability to produce valid and unbiased results. Our first regression model that focuses on assessing the null hypotheses $\mathrm{H}_{01}, \mathrm{H}_{03}, \mathrm{H}_{05}, \mathrm{H}_{07}$ and $\mathrm{H}_{09}$ is as follows:

$$
\begin{aligned}
& \text { BankPerformance }_{i, t}=\beta_{0}+\beta_{1} \times \text { BoardSize }_{i, t}+ \\
& +\beta_{2} \times \text { IndepDir }_{i, t}+\beta_{3} \times \text { FemaleDir}+ \\
& +\beta_{4} \times \text { ForeignDir }_{i, t}+\beta_{5} \times \text { ChairCEO }_{i, t}+ \\
& +\beta_{6} \times \text { ControlVar }_{i, t}+\beta_{7} \times \text { YEAR }_{i, t}+u_{i}+\varepsilon_{i, t}
\end{aligned}
$$

where, the subscripts $i$ denote individual sample banks and $t$ is the time period $(t=2008,2009$, $2010 \ldots, 2014)$. The $(\beta)$ coefficients are the parameters that need to be estimated through our model applications, while ControlVar comprises BankSize, BankCapital, M\&A and Big4Audit, which are the selected control variables. To control for "time-specific effects", we introduce the variable YEAR, which includes the seven individual bank years taking the value of (1) or (0) for each year between 2008 and 2014 to consider the null hypothesis that time has no impact on bank performance ${ }^{5}$. Finally, u symbolizes the "unobserved fixed effect" associated with each sample bank and e stands for the remaining disturbance term.

This study does not limit its research subject only in testing the impact of various corporate governance mechanisms on bank performance, but extends the

\footnotetext{
${ }^{5}$ For the sake of brevity, this paper does not report the analytical findings for the year dummies in Tables 3-5. However, our empirical results suggest no significant impact of time dummies on the performance of Greek banks.
}

empirical analysis in tracing any U-shaped relationships that may exist for the cases of board structure variables that were found to be significant from the application of regression model (1). Therefore, to assess the validity of our null hypotheses $\mathrm{H}_{02}, \mathrm{H}_{04}, \mathrm{H}_{06}$ and $\mathrm{H}_{08}$, we present below indicatively the regression model with the nonlinear relationship on BoardSize:

BankPerformance $_{i, t}=\beta_{0}+\beta_{1} \times$ BoardSize $_{i, t}+$ $+\beta_{2} \times$ BoardSizeSQ $_{i, t}+\beta_{3} \times \operatorname{IndepDir}_{i, t}+$

$+\beta_{4} \times$ FemaleDir $_{i, t}+\beta_{5} \times$ ForeignDir $_{i, t}+$

$+\beta_{6} \times$ ChairCEO $_{i, t}+\beta_{7} \times$ ControlV $_{i, t}+$

$+\beta_{8} \times Y E A R_{i, t}+u_{i}+\varepsilon_{i, t}$.

We begin our empirical analysis with the application of the pooled OLS models. Nevertheless, we should take into account that simple linear regression methodology applied in panel data fails to address the possible correlation between the unobserved effect and the independent variables producing biased and inconsistent results. To overcome this issue, we employ as a second methodology the fixed effects (within estimator) models. Doing so, although we address the problem of unobserved heterogeneity, within estimator models fail to support strict exogeneity condition which is necessary to produce robust results. Thus, we need to employ a methodology that can treat all aforementioned problems in the same time. Following Wooldridge (2002) suggestion, this study chooses to employ the Arellano and Bond (1998) two-step system GMM models with adjusted standard errors to address potential heteroskedasticity problems. The endogeneity issue is a common problem in the governance literature. Following Hermalin and Weisbach (2003), we cannot overlook the possibility that at least to some extend bank performance causes changes in board's composition and ownership structure. However, another advantage of the GMM methodology is that we can use instruments to address endogeneity issues provided that these instruments are not correlated with the error term. Following similar research, we use the Hansen/Sargan test of overidentifying restrictions to test instrument validity.

Although the Hansen/Sargan test can provide reliable results on instrument validity another issue that we have to consider is the possibility of using too many instruments (instrument proliferation problem) putting in jeopardy the reliability of the Hansen/Sargan test results. We address this issue using the "collapse option" of Roodman's (2009) "xtabond2" command in STATA software enhancing the robustness of the instrument validity 
test. Finally, we also control our estimations for $1^{\text {st }}$ and $2^{\text {nd }}$ degree of serial correlation through the application of AR (1) and AR (2) statistics under the null hypotheses that $1^{\text {st }}$ and $2^{\text {nd }}$ degree of serial correlation exists respectively. Existence of $2^{\text {nd }}$ degree of serial correlation suggests that important variables have not been included in our models. Following Liang et al. (2013), we use lags of board structure variables as instruments, since it is logical to assume that future bank performance cannot dictate changes in the board structure of previous years and, therefore, endogeneity should not be an issue. To further increase the robustness of our results and address any downward bias of standard errors and considering that we employ a small sample in our paper present, all our GMM results are reported with the robust adjustment for small samples following Windmeijer's (2000) proposition.

\section{Empirical findings}

In this section, we present exhaustive empirical evidence from the application of pooled OLS, within estimator and GMM models. In our opinion, this methodological approach not only enables to compare our results with the few similar studies on this subject, but also, more importantly, allows to validate the appropriateness of the GMM methodology compared to the other two models employed, namely, pooled OLS and fixed effects models.

3.1. Results of pooled OLS and fixed effects estimations. Table 2 reports the results of the pooled OLS estimations with the introduction of the
BoardSizeSQ variable to test whether reliable results can be produced. The results for all dependent variables (i.e., ROA, ROE, NetInterest and PreTaxOI) imply that continuously increasing the size of the board will lead to increase bank performance without a limit. Interpreting these results, it is not difficult to understand why these findings do not make sense. These results do not only differ from what previous governance literature proposes, but are also opposed to simple logic, because there should be a point at which the appointment of more directors will lead to significant increase of coordination and communication costs, indecisiveness and conflicts. Therefore, although past literature provides convincing evidence in favor of large boards, it is very difficult to believe that continuously increasing boards will always benefit firm performance. These unconvincing findings - which are in consensus with Andres and Vallelado (2008) conclusions on the validity of pooled OLS estimations - can be attributed to the non-consideration of the unobserved heterogeneity and to the problem of endogeneity.

Moreover, OLS findings support that the proportion of independent board members promotes bank performance and the positive relation between the dual appointment of the CEO as Chairman and bank performance. However, pooled-OLS results fail to reject the relevant null hypotheses $\mathrm{H}_{05}$ and $\mathrm{H}_{07}$ for the proportions of female and foreign board members. Finally, the F-test rejects the relevant joint null hypotheses of non-significance for all four models of bank performance.

Table 2. Pooled OLS empirical findings with the inclusion of BoardSizeSQ

\begin{tabular}{|c|c|c|c|c|c|c|c|c|}
\hline Dependent variables & \multicolumn{2}{|c|}{$\mathrm{ROA}$} & \multicolumn{2}{|c|}{ ROE } & \multicolumn{2}{|c|}{ NetInterest } & \multicolumn{2}{|c|}{ PreTaxOl } \\
\hline Explanatory variables & Coef. & P-values & Coef. & P-values & Coef. & P-values & Coef. & P-values \\
\hline BoardSize & 2.313 & $(0.018)^{\star \star}$ & 2.981 & $(0.004)^{\star \star \star}$ & 0.917 & $(0.036)^{\star \star}$ & 2.758 & $(0.021)^{\star \star}$ \\
\hline BoardSizeSQ & 0.093 & $(0.021)^{\star \star}$ & 1.877 & $(0.041)^{\star \star}$ & 0.031 & $(0.057)^{\star}$ & 0.072 & $(0.056)^{*}$ \\
\hline IndepDr & 0.006 & $(0.078)^{*}$ & -0.541 & $(0.031)^{\star \star}$ & 0.003 & $(0.046)^{\star *}$ & 0.005 & $(0.072)^{*}$ \\
\hline FemaleDir & 0.015 & $(0.917)$ & 4.668 & $(0.512)$ & 0.017 & $(0.822)$ & -0.023 & $(0.857)$ \\
\hline ForeignDir & -0.032 & $(0.595)$ & 1.884 & $(0.520)$ & -0.027 & $(0.403)$ & -0.035 & $(0.512)$ \\
\hline ChairCEO & 3.781 & $(0.059)^{*}$ & 2.143 & $(0.052)^{\star}$ & 0.398 & $(0.055)^{*}$ & 3.045 & $(0.139)$ \\
\hline Big4Audit & 0.709 & $(0.001)^{\star \star \star}$ & 1.015 & $(0.069)^{\star}$ & 3.205 & $(0.001)^{\star \star \star}$ & 2.017 & $(0.206)$ \\
\hline BankSize & 2.778 & $(0.003)^{\star \star \star}$ & 1.228 & $(0.005)^{\star \star \star}$ & 1.541 & $(0.003)^{\star \star \star}$ & 2.144 & $(0.002)^{\star \star \star}$ \\
\hline BankCapital & 0.058 & $(0.461)$ & 8.211 & $(0.013)^{* *}$ & 0.014 & $(0.742)$ & 0.034 & $(0.541)$ \\
\hline$M \& A$ & 0.476 & $(0.806)$ & -34.981 & $(0.711)$ & 3.867 & $(0.028)^{* *}$ & 1.339 & $(0.437)$ \\
\hline Constant & 0.339 & $(0.000)^{\star \star \star}$ & 2.831 & $(0.000)^{\star \star \star}$ & 2.747 & $(0.000)^{\star \star \star}$ & 3.209 & $(0.000)^{\star \star \star}$ \\
\hline YEAR & Included & & Included & & Included & & Included & \\
\hline F-statistic & 6.67 & $(0.000)^{\star \star \star}$ & 4.33 & $(0.000)^{\star \star \star}$ & 7.83 & $(0.000)^{\star \star \star}$ & 3.19 & $(0.001)^{\star \star \star}$ \\
\hline Adjusted R-squared & 0.249 & & 0.398 & & 0.360 & & 0.214 & \\
\hline
\end{tabular}

Notes: P-values of coefficient significance are presented in brackets. $(* * *),(* *)$ and $(*)$ denote significance at $1 \%, 5 \%$ and $10 \%$, respectively. This note also applies to subsequent Tables 3-5. 
To solve the fixed effect problem that the pooledOLS models are unable to address, we employ the within estimator following previous researches. Table 3 reports the findings from the application of fixed effects models with the introduction of BoardSizeSQ. These findings are in consensus with Andres and Vallelado (2008) suggesting that a Ushaped relation exists between board size and bank performance. Like pooled OLS results, these findings are against the existing governance literature and do not consider the significant disadvantages of over-sized boards as presented in the section of literature review. The remaining findings are in line with OLS results; The proportion of independent board members significantly promotes bank performance, while CEO-Chairman duality is found also to affect positively the performance of Greek banks. Finally, F-test results imply that all four alternative models of bank performance are significant at $1 \%$.

Table 3. Fixed effects empirical findings with the inclusion of BoardSizeSQ

\begin{tabular}{|c|c|c|c|c|c|c|c|c|}
\hline Dependent variables & \multicolumn{2}{|c|}{ ROA } & \multicolumn{2}{|c|}{$\mathrm{ROE}$} & \multicolumn{2}{|c|}{ Netlnterest } & \multicolumn{2}{|c|}{ PreTaxOI } \\
\hline Explanatory variables & Coef. & P-values & Coef. & P-values & Coef. & P-values & Coef. & P-values \\
\hline BoardSize & -1.582 & $(0.013)^{\star \star}$ & -8.241 & $(0.008)^{\star \star \star}$ & -0.059 & $(0.038)^{\star \star}$ & -0.216 & $(0.017)^{\star \star}$ \\
\hline BoardSizeSQ & 0.043 & $(0.092)^{\star}$ & 2.086 & $(0.073)^{\star}$ & 0.012 & $(0.081)^{*}$ & 0.063 & $(0.065)^{\star}$ \\
\hline IndepDr & 0.086 & $(0.005)^{\star \star}$ & -2.831 & $(0.072)^{\star}$ & 0.025 & $(0.071)^{*}$ & 0.212 & $(0.117)$ \\
\hline FemaleDir & -0.132 & $(0.490)$ & 2.920 & $(0.777)$ & -0.045 & $(0.367)$ & -0.111 & $(0.524)$ \\
\hline ForeignDir & -0.104 & $(0.173)$ & -0.804 & $(0.844)$ & -0.016 & $(0.419)$ & -0.122 & $(0.082)$ \\
\hline ChairCEO & 1.765 & $(0.084)^{\star}$ & 2.737 & $(0.053)^{\star}$ & 0.252 & $(0.053)^{*}$ & 2.371 & $(0.398)$ \\
\hline Big4Audit & 0.593 & $(0.001)^{\star \star \star}$ & 3.074 & $(0.081)^{\star}$ & 1.368 & $(0.008)^{\star \star \star}$ & -2.764 & $(0.621)$ \\
\hline BankSize & 9.678 & $(0.000)^{\star \star \star}$ & 7.838 & $(0.004)^{\star \star \star}$ & 3.118 & $(0.000)^{\star \star \star}$ & 8.511 & $(0.002)^{\star \star \star}$ \\
\hline BankCapital & 0.227 & $(0.016)^{\star \star}$ & 12.063 & $(0.017)^{\star \star}$ & 0.211 & $(0.687)$ & 0.114 & $(0.187)$ \\
\hline M\&A & 2.175 & $(0.331)$ & -5.641 & $(0.966)$ & 3.891 & $(0.028)^{\star \star}$ & 1.186 & $(0.563)$ \\
\hline Constant & 9.305 & $(0.000)^{\star \star \star}$ & 1.547 & $(0.000)^{\star \star \star}$ & 3.599 & $(0.000)^{\star \star \star}$ & 2.649 & $(0.000)^{\star \star \star}$ \\
\hline YEAR & Included & & Included & & Included & & Included & \\
\hline F-statistic & 3.22 & $(0.003)^{\star \star \star}$ & 4.98 & $(0.000)^{\star \star *}$ & 10.27 & $(0.000)^{\star \star \star}$ & 2.57 & $(0.007)^{\star \star \star}$ \\
\hline R-squared within & 0.026 & & 0.132 & & 0.108 & & 0.054 & \\
\hline R-squared between & 0.267 & & 0.375 & & 0.244 & & 0.532 & \\
\hline R-squared overall & 0.176 & & 0.297 & & 0.165 & & 0.297 & \\
\hline
\end{tabular}

To summarize the empirical findings presented from the application of pooled OLS and within estimator with the introduction of BoardSizeSQ variable, these models cannot be trusted to draw firm conclusions, because they lack econometric consistency, are opposed to empirically validated theories on corporate governance and propose unrealistic professional practices ${ }^{5}$. Thus, based on past literature, we are obliged to treat the selected corporate governance variables as endogenous and exclude the possibility of strict exogeneity (Mallin et al., 2014; Mollah and Zaman, 2015; Pathan and Faff, 2013) ${ }^{6}$.

In order to generate reliable results, we need to use an appropriate econometric tool that can

\footnotetext{
${ }^{5}$ Since all models applied fail to support the significant relation between FemaleDir, ForeignDir and bank performance, for the sake of brevity, we choose not to present the resultswith the inclusion of FemaleDirSQ and ForeignDirSQ, since they would not provide any useful information for this study. This note also applies for the case of the subsequent GMM model results. These estimations are available by the author upon request.

${ }^{6}$ We also run the same pooled OLS and fixed effects models with the inclusion of IndepDirSQ to investigate the non-linear links between the proportion of independent board members and bank performance. These findings lead also to questionable results. For the sake of brevity, we choose not to include these findings, although they are available by the authors upon request.
}

simultaneously deal with the potential endogeneity of governance variables and the unobserved heterogeneity of individual banks. The two-step system-GMM models with adjusted standard errors can deal with these problems that threaten the validity of our findings. They solve the problem of heterogeneity by using data in first differences, address the endogeneity of explanatory variables through the inclusion of appropriate instrumentsprovided that they are not correlated with the error term, but are in a position to predict the endogenous variables and using adjusted standard errors, we control for potential heteroskedasticity.

\subsection{Results of two-step system GMM model} estimations. We present the GMM estimator empirical results in Table 4 for all four alternative proxies of bank performance and with the introduction of the BoardSizeSQ variable. These findings verify our implied hypothesis that there should be an inverted U-shaped relation between board size and bank performance provided that BoardSize variable is statistically significant. These results are in line with Andres and Vallelado (2008) results. Considering that large and small bank boards both have significant disadvantages that can negatively affect bank performance, the GMM 
results reject null hypothesis $\mathrm{H}_{02}$ implying that there must be a point at which the continuous appointment of more board members will outbalance the advantages of large boards (e.g., more thorough manager supervision, more human capital to provide advisory services to the managers) leading to increased communication and coordination costs and excessive power to the CEO. Moreover, we observe a positive relationship between the proportion of independent board members and all four measures of bank performance. In contrast with the pooled OLS and within estimator results, GMM findings propose that the dual appointment of the CEO as Chairman decreases bank performance (rejection of $\mathrm{H}_{09}$ ). However, significant results are reported only for the cases of ROA and ROE. GMM results on the proportions of female (FemaleDir) and foreign (ForeignDir) board members do not imply significant relationship with bank performance. These findings are in line with the pooled OLS and within estimator findings.
In regards with the control variables Big4Audit and BankSize significantly promote bank performance. The significant and positive impact of BankSize on bank performance is widely documented in the governance literature. However, BankCapital and M\&A activity do not have significant relationship with the performance of Greek banks. The unexpected absence of statistical significance between BankCapital and bank value could be attributed to the fact that Greek banks are under a financial assistance program since the beginning of the period under study. Thus, any significant impact of capital adequacy on bank performance could be distorted due to the relevant cash injections from various funding programs launched by several intergovernmental organizations. The F-test results reject the joint-null hypothesis of non-significant independent variables. The $\operatorname{AR}(1)$ and $\operatorname{AR}(2)$ statistics do not reject the null hypothesis of no first and second degree of serial correlation, respectively. Finally, the Hansen test results support the validity of the selected instruments.

Table 4. Two-step system GMM empirical findings with the inclusion of BoardSizeSQ

\begin{tabular}{|c|c|c|c|c|c|c|c|c|}
\hline Dependent variables & & & & & & erest & & $\mathrm{xOI}$ \\
\hline Explanatory variables & Coef. & P-values & Coef. & P-values & Coef. & P-values & Coef. & P-values \\
\hline BoardSize & 0.582 & $(0.007)^{\star \star \star}$ & 0.058 & $(0.045)^{\star \star}$ & 0.057 & $(0.068)^{\star}$ & 0.014 & $(0.026)^{\star \star}$ \\
\hline BoardSizeSQ & -0.043 & $(0.070)^{\star}$ & -0.085 & $(0.036)^{* \star}$ & -0.002 & $(0.043)^{\star \star}$ & -0.005 & $(0.077)^{\star}$ \\
\hline IndepDr & 0.088 & $(0.057)^{\star}$ & 0.028 & $(0.0316)^{\star \star}$ & 0.026 & $(0.088)^{\star}$ & 0.011 & $(0.015)^{\star \star \star}$ \\
\hline FemaleDir & -0.132 & $(0.490)$ & 2.920 & $(0.777)$ & -0.045 & $(0.367)$ & -0.011 & $(0.524)$ \\
\hline ForeignDir & -0.104 & $(0.173)$ & -0.804 & $(0.844)$ & -0.016 & $(0.419)$ & -0.192 & $(0.082)$ \\
\hline ChairCEO & -0.765 & $(0.074)^{\star}$ & -0.074 & $(0.089)^{\star}$ & -0.252 & $(0.753)$ & 1.371 & $(0.398)$ \\
\hline Big4Audit & 0.021 & $(0.052)^{*}$ & 0.061 & $(0.068)^{*}$ & 0.327 & $(0.048)^{\star \star}$ & 0.064 & $(0.071)^{*}$ \\
\hline BankSize & 0.876 & $(0.000)^{\star \star \star}$ & 0.837 & $(0.022)^{\star \star}$ & 3.038 & $(0.001)^{\star \star \star}$ & 2.510 & $(0.002)^{\star * \star}$ \\
\hline BankCapital & 0.225 & $(0.619)$ & 2.065 & $(0.118)$ & 0.211 & $(0.812)$ & 0.112 & $(0.689)$ \\
\hline$M \& A$ & 2.177 & $(0.331)$ & -5.639 & $(0.962)$ & -0.091 & $(0.128)$ & 1.189 & $(0.561)$ \\
\hline Constant & 0.310 & $(0.002)^{\star \star \star}$ & 0.058 & $(0.082)^{\star}$ & -0.399 & $(0.073)^{*}$ & -5.379 & $(0.187)$ \\
\hline YEAR & Included & & Included & & Included & & Included & \\
\hline F-statistic & 46.26 & $(0.000)^{\star \star \star}$ & 31.27 & $(0.000)^{\star \star \star}$ & 29.81 & $(0.000)^{\star \star \star}$ & 32.51 & $(0.000)^{* * \star}$ \\
\hline $\mathrm{AR}(1)$ test & -0.85 & $(0.315)$ & -0.76 & $(0.297)$ & -0.58 & $(0.328)$ & -0.98 & $(0.186)$ \\
\hline $\mathrm{AR}(2)$ test & -0.76 & $(0.348)$ & -0.72 & $(0.302)$ & -0.51 & $(0.345)$ & -0.79 & $(0.211)$ \\
\hline Hansen/Sargan test & 78.58 & $(0.297)$ & 68.47 & $(0.188)$ & 55.20 & $(0.140)$ & 63.20 & $(0.179)$ \\
\hline
\end{tabular}

Having documented in Table 4 the significant impact of the proportion of independent board members on bank performance, Table 5 reports the GMM model results with the introduction of IndepDirSQ, which replaces the BoardSizeSQ. An inverted U-shaped relation is also documented for the case of independent directors. These results are in line with governance theory and past researches. Additions of independent directors can bring an alternative perspective on how managers deal with the bank's problems, increase the protection of shareholder's interests and reduce the conflicts of interest within the organization. However, as findings indicate, there is a point where the benefits from adding more independent board members reaches to a maximum. Too many independent board members - especially if they do not have adequate skills or relevant professional experience in similar organizations - may lead to opposite results damaging bank performance. Considering that independent board members are not working for the company they do not have in-depth knowledge of the company's internal processes, culture or individual bank characteristics.

Moreover, it should be highlighted that the significant contribution of board size has been eliminated from Table 5 results after we replaced the BoardSizeSQ variable with IndepDirSQ. These 
findings could imply that the inverted U-shaped relation between independent directors and bank performance is the reason behind the concave relationship between BoardSize and proxies of bank value. However, such a generalization may be risky, considering that our models fail to provide statistically significant evidence for the links between other proxies of board composition (i.e., FemaleDir and ForeignDir) and bank performance.
The findings for the remaining explanatory variables do not differ much from those of Table 4. The CEO-Chairman duality appears to affect negatively bank value only in the cases of ROA and ROE at $10 \%$ level, while the appointment of a Big4 firm as an auditor continues to present significantly positive results on bank value. BankSize significantly promotes bank value at $1 \%$ significance level as in Table 4. Finally, all model validity tests verify the robustness of our findings.

Table 5. Two-step system GMM empirical findings with the inclusion of IndepDirSQ

\begin{tabular}{|c|c|c|c|c|c|c|c|c|}
\hline \multirow{2}{*}{$\begin{array}{l}\text { Dependent variables } \\
\text { Explanatory variables }\end{array}$} & \multicolumn{2}{|c|}{$\mathrm{ROA}$} & \multicolumn{2}{|c|}{ ROE } & \multicolumn{2}{|c|}{ NetInterest } & \multicolumn{2}{|c|}{ PreTaxOI } \\
\hline & Coef. & P-values & Coef. & P-values & Coef. & P-values & Coef. & P-values \\
\hline BoardSize & -0.416 & $(0.132)$ & -0.002 & $(0.123)$ & -0.007 & $(0.135)$ & -0.005 & $(0.186)$ \\
\hline IndepDr & 0.273 & $(0.043)^{\star \star}$ & 0.366 & $(0.023)^{\star \star}$ & 0.128 & $(0.056)^{\star}$ & 0.356 & $(0.083)^{\star}$ \\
\hline IndepDrSQ & -0.253 & $(0.078)^{\star}$ & -0.461 & $(0.055)^{\star}$ & -0.106 & $(0.011)^{\star \star}$ & -0.003 & $(0.068)^{*}$ \\
\hline FemaleDir & -0.175 & $(0.312)$ & 0.997 & $(0.915)$ & -0.036 & $(0.415)$ & -0.185 & $(0.246)$ \\
\hline ForeignDir & -0.094 & $(0.203)$ & -0.379 & $(0.924)$ & -0.018 & $(0.355)$ & -0.106 & $(0.120)$ \\
\hline ChairCEO & -0.265 & $(0.082)^{\star}$ & 0.005 & $(0.061)^{*}$ & -0.092 & $(0.700)$ & -0.541 & $(0.328)$ \\
\hline Big4Audit & 0.147 & $(0.042)^{\star *}$ & 0.015 & $(0.054)^{\star}$ & -0.183 & $(0.067)^{\star}$ & -0.002 & $(0.069)^{*}$ \\
\hline BankSize & 1.199 & $(0.001)^{\star \star \star}$ & 0.478 & $(0.008)^{\star \star \star}$ & 1.152 & $(0.001)^{\star \star \star}$ & 3.799 & $(0.002)^{\star \star \star}$ \\
\hline BankCapital & 0.234 & $(0.614)$ & 0.413 & $(0.115)$ & 0.211 & $(0.831)$ & 0.121 & $(0.657)$ \\
\hline$M \& A$ & 2.714 & $(0.176)$ & 1.393 & $(0.852)$ & -0.872 & $(0.097)$ & 0.096 & $(0.308)$ \\
\hline Constant & -83.412 & $(0.000)^{\star \star \star}$ & -1304.608 & $(0.283)^{\star \star \star}$ & -25.865 & $(0.000)^{\star \star \star}$ & -67.442 & $(0.000)^{\star \star \star}$ \\
\hline YEAR & Included & & Included & & Included & & Included & \\
\hline F-statistic & 86.58 & $(0.000)^{* * *}$ & 45.67 & $(0.000)^{\star \star \star}$ & 29.98 & $(0.000)^{\star \star \star}$ & 151.57 & $(0.000)^{\star \star \star}$ \\
\hline $\mathrm{AR}(1)$ test & -0.76 & $(0.288)$ & -0.87 & $(0.327)$ & -0.46 & $(0.269)$ & -0.97 & $(0.197)$ \\
\hline $\mathrm{AR}(2)$ test & -0.67 & $(0.323)$ & -0.66 & $(0.347)$ & -0.45 & $(0.288)$ & -0.85 & $(0.205)$ \\
\hline Hansen/Sargan test & 50.57 & $(0.113)$ & 56.83 & $(0.147)$ & 68.54 & $(0.177)$ & 79.97 & $(0.291)$ \\
\hline
\end{tabular}

\section{Concluding remarks and policy implications}

The governance literature specialized in the banking industry experiences significant growth in the recent years. However, until present, only few empirical studies have been published assessing the corporate governance-bank performance nexus. This paper, motivated by the few past researches on this area, provides exhaustive empirical evidence for the case of the Greek banking system and for a period (2008-2014) that is marked by severe sovereign debt crisis. This study provides the first in-depth empirical analysis assessing the impact of corporate governance mechanisms on the Greek banking industry employing most of the accepted methodological tools and variables used in the governance literature, to the best of our knowledge. Thus, this paper provides valuable information in regards with the validity of the selected methodologies, produces empirical evidence for the Greek banks where relevant empirical research is almost absent, but, more importantly, examines whether corporate governance mechanisms do have significant impact on bank performance even for a period that is characterized by high market volatility, macroeconomic instability and liquidity constraints.
In conclusion, our empirical applications and comparative analysis indicate the superiority of the two-step system GMM models to address simultaneously frequently encountered econometric problems when dealing with governance variables, such as the unobserved individual effect of each bank, the endogeneity andthe simultaneity. Robust results imply that inverted U-shaped relations exist between board size and the performance of Greek banksand between the proportion of independent board members and bank value (rejection of the null hypotheses $\mathrm{H}_{01}, \mathrm{H}_{02}, \mathrm{H}_{03}$ and $\mathrm{H}_{04}$ ).

Thus, we urge regulators and policy makers in Greece to further enforce and monitor the implementation of the governance regulatory framework in the banking industry with special focus on these two characteristics making necessary improvements in the relevant legislation where necessary. Nevertheless, these results should be interpreted with caution considering that the positive effects of appointing more board members (especially independent members as results imply) reaches to a maximum where thereafter new additions of directors/independent directors could damage the performance of Greek banks. Therefore, continuous monitoring and reevaluations on the 
impact of these two board structure variables on bank value are strongly recommended. Furthermore, Greek banks should choose carefully the new additions of independent board members. They should have solid professional background in the banking sector, familiarity and continuous update on the unique characteristics of the bank that serve as independent directors, and ideally management experience from banks abroad.

Moreover, this study fails to document any significant impact of other board structure variables employed namely, the proportions of female and foreign board members. However, considering that these proportions are quite small for the case of Greek banks and that the penetration of corporate governance culture seems to follow a slow pace in Greece, we urge fellow researchers to revisit these variables in the future. Greek banks should also consider the negative impact on their value because of CEO-Chairman duality. Our empirical analysis provides evidence of a weakly significant and negative impact of the Chairman-CEO combined role on bank value. These findings are in line with several similar studies (see Yermack, 1996; Khanchel, 2007; Mollah and Zaman, 2015). Therefore, we suggest with some hesitations, however, that the dual appointment of the CEO as Chairman should be avoided for the case of the Greek banking industry, since it gives too much power to one individual and this, in turn, may hurt the interests of the shareholders and increase the agency problem.

Finally, we propose some potentially useful policy implications that can be implied from interpreting the positive (however weak) impact of the Big4Audit control variable on bank performance as documented in our GMM estimations. Although we treat this variable as an individual bank characteristic, these findings could imply that the appointment of an external auditor that has a strong brand name and global know-how in the provision of auditing services, can contribute to the conformity of the bank with the governance regulatory framework and increase shareholder's confidence on the quality of the audit performed. This could prove beneficial especially in the case of Greece, where the lack of society's confidence in the banking system is very high due to the crisis. Thus, we urge banks to appoint auditors with worldwide reputation and experience. This, in turn, may lead to multiple benefits for the bank ranging from up-to-date audit processes to potentially increasing bank performance. Regardless the debate arising from this suggestion, it should be acceptable that a diligent audit performed by specialized and well-qualified professionals enhances the transparency of financial statements, the confidence of shareholders and among others the bank's compliance with the mandatory (and, in some cases, voluntary) aspects of the Greek corporate governance legislation.

\section{References}

1. Adams, R. B., Mehran, H. (2012). Bank board structure and performance: evidence for large bank holding companies. Journal of Financial Intermediation, 21, 243-267.

2. Adams, R. B., Ferreira, D. (2009). Women in the boardroom and their impact on governance and performance. Journal of Financial Economics, 94, 291-309.

3. Adams, R. B., Hermalin, B., Ferreira, D. (2005). Powerful CEOs and their impact on corporate performance. Review of Financial Studies, 18 (4), 1403-1432.

4. Adams, R. B., Mehran, H. (2005). Corporate performance, board structure and its determinants in the banking industry. Working Paper, SSRN.

5. Adams, R. B., Mehran, H. (2003). Is corporate governance different for bank holding companies? Federal Reserve Bank of New York Economic Policy Review, 123-142.

6. Agrawal, A., Knoeber, C. (1996). Firm performance and mechanisms to control agency problems between managers and shareholders. Journal of Financial and Quantitative Analysis, 31(3), 377-397.

7. Andres, P., Vallelado, E. (2008). Corporate governance in banking: the role of board of directors. Journal of Banking and Finance, 32, 2570-2580.

8. Arellano, M., Bond, S. (1998). Dynamic panel data estimation using DPD98 for GAUSS: A guide for users. Working Paper, Institute for Fiscal Studies.

9. Basel Committee on Banking Supervision. (2006). Enhancing Corporate Governance for Banking Organizations.

10. BCBS. (2005). International Convergence of Capital Measurement and Capital Standards: A Revised Framework. Consultative Document.

11. Brickley, J. A., Coles, J. L., Jarrell, G. (1997). Leadership structure: separating the CEO and chairman of the board. Journal of Corporate Finance, 3, 189-220.

12. Caprio, G., Levine, R. (2002). Corporate governance of banks: concepts and international observations. Paper Presented at the Global Corporate Governance Forum Research Network Meeting 2002.

13. Carter, D. A., Simkins, B. J., Simpson, W.G. (2003). Corporate governance, board diversity, and firm value. The Financial Review, 38, 33-53.

14. Catalyst. (2010). Catalyst Census of Women Board Directors of the Fortune 500, Catalyst, New York, NY. 
15. Coles, J.L., Daniel, N.D., Naveen, L., 2008. Boards: does one size fit all? Journal of Financial Economics, 87, 329-356.

16. Deya, A., Engelb, E., Liuc, X. (2011). CEO and board chair roles: To split or not to split? Journal of Corporate Finance, 17(5), 1595-1618.

17. Eagly, A., Carli, L. (2003). The female leadership advantage: an evaluation of the evidence. The Leadership Quarterly, 14, 807-834.

18. Eisenberg, T., Sundgren, S., Wells, M. T. (1998). Larger board size and decreasing firm value in small firms. Journal of Financial Economics, 48, 35-54.

19. Grose, C., Kargidis, T., Chouliaras, V. (2014). Corporate governance in practice. The Greek case. Procedia Economics and Finance, 9, 369-379.

20. Gul, F. A., Srinidhi, B., Ng, A. C. (2011). Does board gender diversity improve the informativeness of stock prices? Journal of Accounting and Economics, 51, 314-338.

21. Hahn, D. P., Lasfer, M. (2016). Impact of foreign directors on board meeting frequency. International Review of Financial Analysis, 46, 295-308.

22. Harris, M., Raviv, A. (2008). A theory of board control and size. Review of Financial Studies, 21(4), $1797-1832$.

23. Hermalin, B. E., Weisbach, M. S. (2003). Boards of directors as an endogenously determined institution: a survey of the economic literature. Federal Reserve Bank of New York Economic Policy Review, 9, 7-26.

24. James, J. B., Joseph, C. (2015). Corporate governance mechanisms and bank performance: resource-based view. Procedia Economics and Finance, 31, 117-123.

25. Khanchel, I. (2007). Corporate governance: measurement and determinate analysis. Managerial Auditing Journal, $22,740-760$.

26. Klein, A. (2002). Audit committee, board of director characteristics, and earnings management. Journal of Accounting and Economics, 35, 375-400.

27. Liang, Q., Xu, P., Jiraporn, P. (2013). Board characteristics and Chinese bank performance. Journal of Banking and Finance, 37, 2953-2968.

28. Linck, J. S., Netter, J. M., Yang, T. (2008). A large sample study on board changes and determinants of board structure. Journal of Financial Economics, 87, 308-328.

29. Lorsch, J. W., Lipton, M. (1993). On the leading edge: The lead director. Harvard Business Review, 71(1), 79-80.

30. Mallin, C., Farag, H., Ow-Yong, K. (2014). Corporate social responsibility and financial performance in Islamic banks. Journal of Economic Behavior \& Organization, 103, 521-538.

31. Mollah, S., Zaman, M. (2015). Shari'ah supervision, corporate governance and performance: Conventional vs. Islamic banks. Journal of Banking and Finance, 58, 418-435.

32. Nguyen, B. D., Nielsen, K. M. (2010). The value of independent directors: evidence from sudden death. Journal of Financial Economics, 98, 550-567.

33. Pathan, S., Faff, R. (2013). Does board structure in banks really affect their performance? Journal of Banking and Finance, 37, 1573-1589.

34. Peck-Ling, T., Nai-Chiek, A., Chee-Seong, L. (2016). Foreign ownership, foreign directors and the profitability of Malaysian listed companies. Procedia - Social and Behavioral Sciences, 219, 580-588.

35. Pi, L., Timme, S.G. (1993). Corporate control and bank efficiency. Journal of Banking and Finance, 17, 515-530.

36. Raheja, C.G. (2005). The determinants of board size and composition: a theory of corporate boards. Journal of Financial and Quantitative Analysis, 40, 283-306.

37. Roodman, D. (2009). How to do xtabond2: An introduction to "difference" and "system" GMM in Stata. Stata Journal, 9, 86-136.

38. Windmeijer, F. (2000). A finite sample correction for the variance of linear two-step GMM estimators. Working Paper. The Institute for Fiscal Studies.

39. Wintoki, M. B., Linck, J. S., Netter, J. M. (2012). Endogeneity and the dynamics of corporate governance. Journal of Financial Economics, 105, 581-606.

40. Yermack, D. (1996). Higher market valuation of companies with a small board of directors. Journal of Financial Economics, 40, 185-212. 